\title{
Pengembangan Rumah Sakit Umum ISlam MadinaH dengan Penerapan Healing Environment di Kabupaten Malang
}

\author{
Wiwid Lantika Ramdani, Hadi Setyawan, Agus Heru Purnomo \\ Program Studi Arsitektur \\ Fakultas Teknik \\ Universitas Sebelas Maret Surakarta \\ Email : ramdani.lrwl@gmail.com
}

\begin{abstract}
Healthcare need in Malang increasing especially on Madinah General Islamic Hospital. The hospital service capacity equivalent to C Class standard Ministry of Health $(\mathrm{MoH})$ today, has not been able to accommodate and handle some of the facilities which include several other specialist medical services, basic sub spesialist medical services also teeth and mouth specialist medical services. Many patients are referred to the regional hospital which mileage distance far enough, and the lack of the number of patient beds becomes the main establishment background of this project. How spatial meet the needs of all health service activities were comfortable and toward healing environment and in accordance with the rules of Islam. Hospitals with the application of this Healing Environment enabled to answer the needs of people to obtain health care facilities as well as get relief faster. The goal is how to realize the hospital is able to provide health services to the healing process faster and neighborhoods to actively participate in the healing process of patients were able to control the development, including privacy, increasing social support, giving access to a natural and positive distraction else that helps improve medical results. There was established concepts that support healing process: the procurement of green space for higher quality air supply as well as a means of interaction between the patient, the openings which allows patients to access view, optimization of natural lighting and air conditioning, as well as the use of colors and materials that help reduce stress.
\end{abstract}

Keyword: Healing Environment,Malang, General Hospital

\section{PENDAHULUAN}

Proyek ini memiliki nama "Pengembangan Rumah Sakit Umum Islam Madinah sesuai Standar Kelas B di Kabupaten Malang dengan Penerapan Healing Environment". Proyek ini bersifat fiktif dan dimiliki oleh swasta yang sebelumnya sudah memiliki rumah sakit yang kelasnya setara dengan Kelas C standar Kementrian Kesehatan RI.

Rumah Sakit Umum sesuai Standar Kelas B menurut Departemen Kesehatan RI (2010) adalah sarana kesehatan masyarakat umum yang mempunyai fasilitas dan kemampuan sekurang-kurangnya empat pelayanan medik spesialis dasar yaitu penyakit dalam, obstetri dan ginekologi, bedah dan kesehatan anak; empat pelayanan spesialis penunjang medik terpilih yaitu:
Radiologi, Patologi Klinik, Anestesi dan Rehabilitasi Medik; delapan pelayanan medik spesialis lain terpilih yaitu: Telinga Hidung dan Tenggorokan (THT), Mata, Kulit dan Kelamin, Syaraf, Gigi dan Mulut, Jantung, Paru, Ortopedi; dua pelayanan medik subspesialis dasar yaitu bedah dan penyakit dalam di kabupaten.

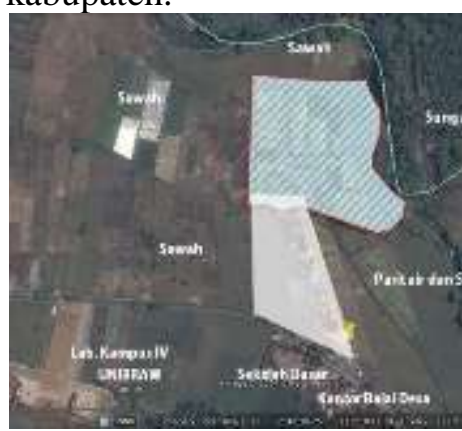

Gambar 1. Batas tapak 
Pengembangan Rumah Sakit Umum Islam Madinah berlokasi di Desa Sukosari, Kecamatan Kasembon, Kabupaten Malang batas tapaknya ditunjukkan pada Gambar 1 . Pengembangan rumah sakit ini dilatar belakangi oleh pesatnya pertambahan kebutuhan pelayanan rumah sakit secara umum di Indonesia yang ditandai dengan peningkatan jumlah penduduk tidak sebanding dengan ketersediaan fasilitas pelayanan kesehatan, khususnya di Kabupaten Malang yang masih kekurangan sejumlah 433 tempat tidur (http://sirs.buk.depkes.go.id, 2014). Rumah Sakit Umum Islam Madinah Kasembon memegang peran peting sebagai rujukan pelayanan kesehatan masyarakat yang tinggal di wilayah Malang Barat dan sekitarnya dikarenakan untuk mencapai rumah sakit yang memiliki fasilitas lebih lengkap di pusat kota harus menempuh perjalanan sejauh $\pm 87 \mathrm{~km}$. Selain jarak tempuh yang tidak efisien kondisi lingkungan internal RSUI Madinah yang kurang kondusif berpengaruh terhadap psikologi dan tingkat kepuasan pasien. Perbedaan latar belakang agama, kultur, sosial, ekonomi masyarakat melahirkan beragam tuntutan yang harus dipenuhi oleh Rumah Sakit Umum Islam Madinah di Malang.

\section{METODE}

Menurut Knecht dalam Lidayana (2013), Healing Environment adalah pengaturan fisik dan dukungan budaya yang memelihara fisik, intelektual, sosial dan kesejahteraan spiritual pasien, keluarga dan staf serta membantu mereka untuk mengatasi stres terhadap penyakit dan rawat inap. Menurut Malkin dalam Montague dalam Lidayana (2013), Healing Environment adalah pengaturan fisik yang mendukung pasien dan keluarga untuk menghilangkan stres yang disebabkan oleh penyakit, rawat inap, kunjungan medis, pemulihan dan berkabung. Dengan demikian, dapat disimpulkan bahwa Healing Environment merupakan suatu desain lingkungan terapi yang dirancang untuk membantu proses pemulihan pasien secara psikologis

Psikolog lingkungan Roger Ulrich, Ph.D. (2000) menulis bahwa lingkungan pelayanan kesehatan seharusnya dapat menghilangkan karakteristik lingkungan yang diketahui akan menyebabkan stres atau dapat memberikan dampak negatif langsung terhadap kesembuhan (suara keras, misalnya), karakteristik dan peluang dalam lingkunganbahwa penelitian menunjukkan dapat menenangkan pasien, mengurangi stres, serta memperkuat mengatasi sumber daya dan proses kesembuhan. Menurut Ulrich (2000), lingkungan kesehatan yang mendukung tersebut di antaranya adalah: kontrol pembantu perkembangan, termasuk privasi; meningkatkan dukungan sosial; dan memberikan akses ke alam dan pegalihan positif lainnya.

Menurut Murphy dalam Lidayana (2013), ada tiga pendekatan yang digunakan dalam mendesain healing environment, yaitu alam, indra dan psikologis. Berikut penjelasan dari masing-masing pendekatan desain:

1. Alam

Alam merupakan alat yang mudah diakses dan melibatkan pancaindra. Alam memiliki efek restoratif seperti menurunkan tekanan darah, memberikan konstribusi bagi keadaan emosi yang positif, menurunkan kadar hormon stres dan meningkatkan energi. Unsur alam yang ditempatkan ke dalam pengobatan pasien dapat membantu menghilangkan stres yang diderita pasien.

2. Indera

Indra meliputi pendengaran, penglihatan, peraba, penciuman dan perasa. Masingmasing indra dapat dijelaskan sebagai berikut:

a. Indera pendengaran

Suara yang menyenangkan dapat mengurangi tekanan darah dan detak jantung sehingga menciptakan sen-sasi kenikmatan yang mempenga-ruhi sistem saraf.

b. Indera penglihatan

Sesuatu yang dapat membuat mata menjadi santai/relax seperti pemandangan, cahaya alami, karya seni dan penggunaan warna tertentu.

c. Indera peraba

Sentuhan merupakan mekanisme dasar dalam menjelajahi dunia selama masa kanak-kanak karena sentuhan menegaskan apa yang mereka lihat, cium, rasa dan dengar.

d. Indera penciuman 
Wiwid L. Ramdani, Hadi Setyawan, Agus Heru, Rumah Sakit...

Bau yang menyenangkan dapat menurunkan tekanan darah dan detak jantung, sedangkan bau yang tidak menyenangkan dapat meningkatkan detak jantung dan pernapasan.

e. Indera perasa

Indra perasa menjadi terganggu pada saat pasien mengalami sakit ataupun menerima pengobatan. Hal ini biasanya ditunjukkan dengan berubahnya rasa makanan maupun minuman saat dikonsumsi. Karena itu, kualitas makanan dan minuman yang ditawarkan harus diperhatikan.

\section{Psikologis}

Secara psikologis, healing environment membantu proses pemulihan pasien menjadi lebih cepat, mengurangi rasa sakit dan stres. Perawatan pasien yang diberikan memperhatikan terhadap pilihan, kebutuhan dan nilai-nilai yang menuntun pada keputusan klinis pasien. Ada enam dimensi untuk perawatan pasien, antara lain:

a. Rasa kasih sayang, empati dan tanggapan terhadap kebutuhan

b. Koordinasi dan integrasi

c. Informasi dan komunikasi

d. Kenyamanan fisik

e. Dukungan emosional

f. Keterlibatan keluarga dan teman-teman

\section{ANALISIS}

\subsection{Analisis Peruangan}

Besaran ruang terpilih berdasarkan besaran acuan yang disyaratkan pada buku Pedoman Sarana dan Prasarana Rumah Sakit Kelas B disesuaikan dengan jumlah pelayanan terpilih yang direncanakan (lihat Tabel 1).

Tabel 1.Luas ruang berdasarkan fungsinya

\begin{tabular}{|l|l|c|}
\hline No & \multicolumn{1}{|c|}{ Area } & $\begin{array}{c}\text { Luasan } \\
\left(\mathbf{m}^{\mathbf{2}}\right)\end{array}$ \\
\hline 1 & Instalasi Rawat Jalan (IRJ) & 617 \\
\hline 2 & Instalasi Gawat Darurat (IGD) & 1082 \\
\hline 3 & Instalasi Rawat Inap (IRNA) & 5956 \\
\hline 4 & $\begin{array}{l}\text { Instalasi Perawatan Intensif } \\
\text { (ICU/ICCU/NICU) }\end{array}$ & 368 \\
\hline 5 & Instalasi Bedah & 713 \\
\hline 6 & $\begin{array}{l}\text { Instalasi Kebidanan dan } \\
\text { Penyakit Kandungan }\end{array}$ & 950 \\
\hline 7 & Instalasi Rehabilitasi Medik & 1096 \\
\hline 8 & Haemodialisa & 296 \\
\hline 9 & Radioterapi & 358 \\
\hline
\end{tabular}

\begin{tabular}{|c|l|c|}
\hline 10 & Kedokteran Nuklir & 237 \\
\hline 11 & Unit Farmasi & 810 \\
\hline 12 & Instalasi Radio Diagnosis & 324 \\
\hline 13 & Laboratorium & 332 \\
\hline 14 & UTD/BDRS & 250 \\
\hline 15 & Instalasi Diagnosis Terpadu & 440 \\
\hline 16 & $\begin{array}{l}\text { Pemulasaran Jenazah dan } \\
\text { Forensik }\end{array}$ & 444 \\
\hline 17 & $\begin{array}{l}\text { Instalasi Sterilisasi Pusat } \\
\text { (CSSD) }\end{array}$ & 280 \\
\hline 18 & Linen & 239 \\
\hline 19 & Instalasi Sanitasi & 208 \\
\hline 20 & Instalasi Pemeliharaan Sarana & 292 \\
\hline 21 & Masjid & 559 \\
\hline 22 & Pendukung Lain & 8915 \\
\hline 23 & Administrasi dan Manajemen & 1136 \\
\hline Jumlah Total Kebutuhan & 26259 \\
\hline
\end{tabular}

Pada Tabel 1. menunjukkan kebutuhan luasan dalam perancangan rumah sakit Kelas B.

\subsection{Analisis Tapak}

Analisis tapak meliputi pemintakatan privasi, resiko, sirkulasi dan pencapaian.

\subsubsection{Tujuan}

Mintakat berdasarkan privasi, jenis pelayanan dan tingkat resiko, sirkulasi dan pencapaian

\subsubsection{Dasar pertimbangan:}

Keamanan, kenyamanan, kemudahan akses.

Minimalisir debu dan kebisingan

Minimalisir eksploitasi alam (cut \& fill)

\subsubsection{Proses analisis.}

\subsubsection{Pemintakatan privasi}

Pemintakatan berdasarkan privasi dan area pembagiannya ditunjukkan pada Gambar 2 . serta diuraikan pada Tabel 2.

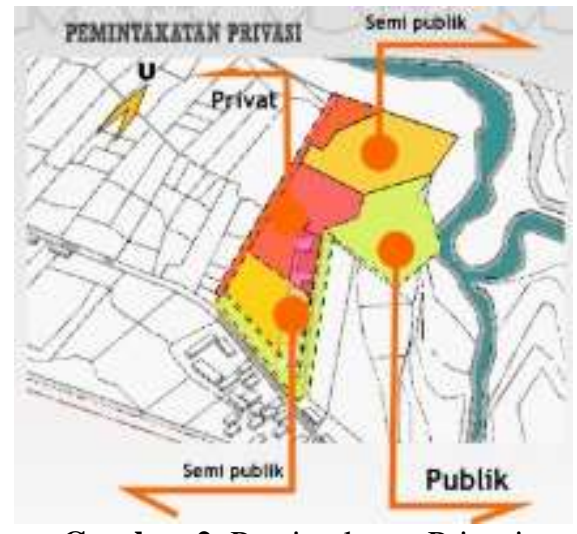

Gambar 2. Pemintakatan Privasi 
Tabel 2. . Analisa Pemintakatan Privasi

\begin{tabular}{|c|c|c|}
\hline Mintakat & Persyaratan & Jenis ruang \\
\hline Publik & $\begin{array}{c}\text { akses langsung } \\
\text { dengan lingkungan } \\
\text { luar rumah sakit }\end{array}$ & $\begin{array}{c}\text { Poliklinik, IGD, } \\
\text { Apotek }\end{array}$ \\
\hline $\begin{array}{l}\text { Semi } \\
\text { publik }\end{array}$ & $\begin{array}{c}\text { tidak berhubungan } \\
\text { langsung dengan } \\
\text { lingkungan luar, } \\
\text { menerima beban } \\
\text { kerja dari area } \\
\text { publik }\end{array}$ & $\begin{array}{c}\text { Laboratorium, } \\
\text { Radiologi, } \\
\text { Rehabilitasi } \\
\text { Medik }\end{array}$ \\
\hline Privat & $\begin{array}{l}\text { Area yang dibatasi } \\
\text { bagi pengunjung } \\
\text { rumah sakit, } \\
\text { umumnya area } \\
\text { tertutup }\end{array}$ & $\begin{array}{c}\text { ICU/ICCU, } \\
\text { Bedah, } \\
\text { Kebidanan dan } \\
\text { Kandungan, } \\
\text { Rawat Inap }\end{array}$ \\
\hline
\end{tabular}

\subsubsection{Pemintakatan resiko}

Pemintakatan berdasarkan tingkat resiko dan area pembagiannya ditunjukkan pada Gambar 3. serta diuraikan pada Tabel 3.

Tabel 3. Analisa Pemintakatan Resiko

\begin{tabular}{|l|l|l|}
\hline Mintakat & Persyaratan & Jenis ruang \\
\hline $\begin{array}{l}\text { Resiko } \\
\text { Randah }\end{array}$ & $\begin{array}{l}\text { Non- } \\
\text { pelayanan } \\
\text { medis }\end{array}$ & $\begin{array}{l}\text { ruang kesekretariatan } \\
\text { dan administrasi, } \\
\text { ruang komputer, } \\
\text { ruang pertemuan, } \\
\text { ruang arsip/rekam } \\
\text { medis. }\end{array}$ \\
\hline $\begin{array}{l}\text { Resiko } \\
\text { Sedang }\end{array}$ & $\begin{array}{l}\text { Non-infeksius } \\
\text { Stabil }\end{array}$ & $\begin{array}{l}\text { ruang rawat inap non- } \\
\text { penyakit menular, } \\
\text { rawat jalan }\end{array}$ \\
\hline $\begin{array}{l}\text { Resiko } \\
\text { Tinggi }\end{array}$ & $\begin{array}{l}\text { Rentan } \\
\text { kontaminan } \\
\text { Tidak stabil } \\
\text { Radiasi }\end{array}$ & $\begin{array}{l}\text { ruang isolasi, ruang } \\
\text { ICU/ICCU, } \\
\text { laboratorium, } \\
\text { pemulasaraan jenazah } \\
\text { dan ruang bedah mayat, } \\
\text { ruang radiodiagnostik }\end{array}$ \\
\hline $\begin{array}{l}\text { Resiko } \\
\text { Sangat } \\
\text { Tinggi }\end{array}$ & $\begin{array}{l}\text { Infeksius } \\
\text { Kentan }\end{array}$ & $\begin{array}{l}\text { ruang bedah, IGD, } \\
\text { ruang bersalin, ruang } \\
\text { patolog }\end{array}$ \\
\hline
\end{tabular}

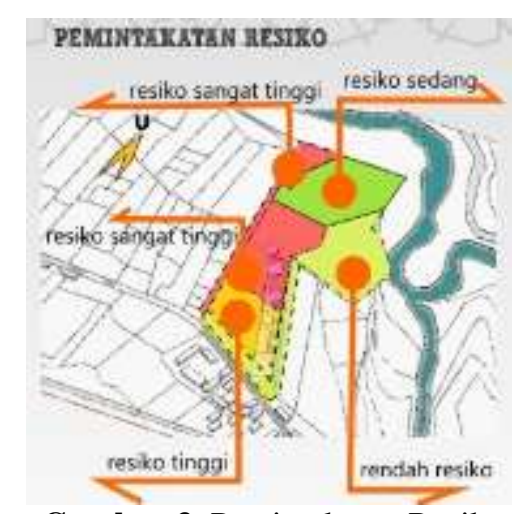

Gambar 3. Pemintakatan Resiko
Prinsip umumnya pencapaian ke dalam bangunan harus mudah diakses, mudah dilihat dan memiliki sirkulasi yang aman akan menstimulus orang untuk masuk dalam area bangunan. Pemintakatan berdasarkan jalur sirkuasi dan area pembagiannya ditunjukkan pada Gambar 4. serta diuraikan pada Tabel 4.

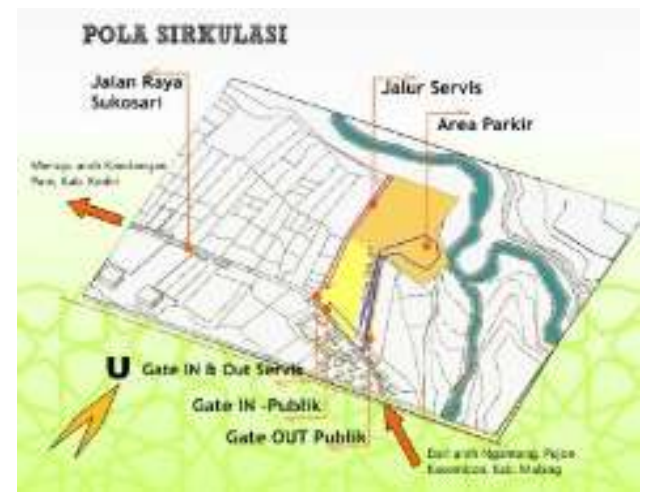

Gambar 4. Pola Pencapaian

Tabel 4. Analisa Jalur Pencapaian

\begin{tabular}{|c|c|c|}
\hline Mintakat & $\begin{array}{l}\text { Persya- } \\
\text { ratan }\end{array}$ & Jenis ruang \\
\hline $\begin{array}{l}\text { Sirkulasi } \\
\text { Publik }\end{array}$ & $\begin{array}{l}\text { Jalur } \\
\text { utama, } \\
\text { intensitas } \\
\text { tinggi, } \\
\text { Main } \\
\text { Entrance }\end{array}$ & $\begin{array}{l}\text { Jalur yang } \\
\text { diperuntukkan bagi } \\
\text { pasien, pengunjung, } \\
\text { dan tenaga medis, }\end{array}$ \\
\hline $\begin{array}{l}\text { Sirkulasi } \\
\text { Servis }\end{array}$ & $\begin{array}{l}\text { Akses } \\
\text { terbatas, } \\
\text { intensitas } \\
\text { rendah, } \\
\text { Side } \\
\text { Entrance }\end{array}$ & $\begin{array}{lr}\begin{array}{lr}\text { Jalur yang } \\
\text { diperuntukkan }\end{array} & \begin{array}{r}\text { khusus } \\
\text { petugas }\end{array} \\
\text { diantaranya } & \text { servis } \\
\text { mengangkut } & \text { sampah, } \\
\text { limbah } & \text { khusus, } \\
\text { logistik, } & \text { keperluan } \\
\text { mekanik } & \text { serta } \\
\text { kegiatan } & \text { servis lain } \\
\text { yang } & \text { dihindarkan } \\
\text { terlihat } & \text { oleh } \\
\text { pengunjung } & \text { rumah } \\
\text { sakit } & \end{array}$ \\
\hline
\end{tabular}

\subsection{Analisis Klimatologi}

\subsubsection{Penyinaran Matahari}

Penyinaran sinar matahari tropis secara penuh sepajang tahun, membutuhkan perlakuan khusus agar sinar tidak menyebabkan suhu ruang sehingga melewati batas kenyamanan thermal (lihat Gambar. 5).

\subsubsection{Pencapaian}




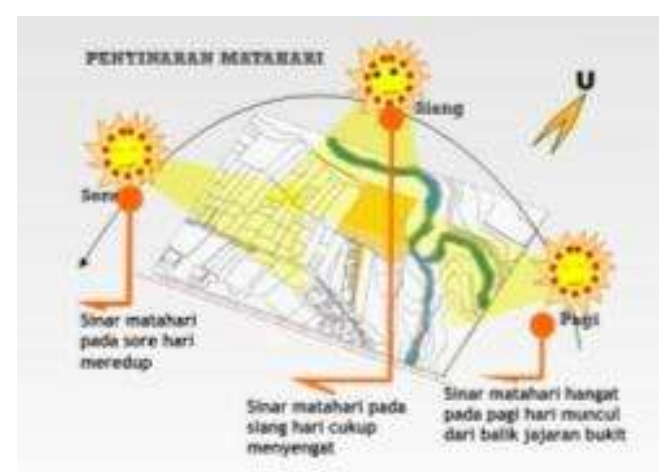

Gambar 5. Analisa Pencahayaan

1. Sinar matahari alami pada pagi hari harus dapat diakses oleh pasien;

2. Menghindari paparan sinar matahari siang hingga sore hari secara langsung pada ruang;

3. Pencahayaan alami lebih diutamakan atas pencahayaan buatan.

\subsubsection{Air Hujan}

Aliran air hujan mengarah pada kontur tanah yang lebih rendah, dan atap rawan tampias oleh hempasan angin (lihat Gambar.6).

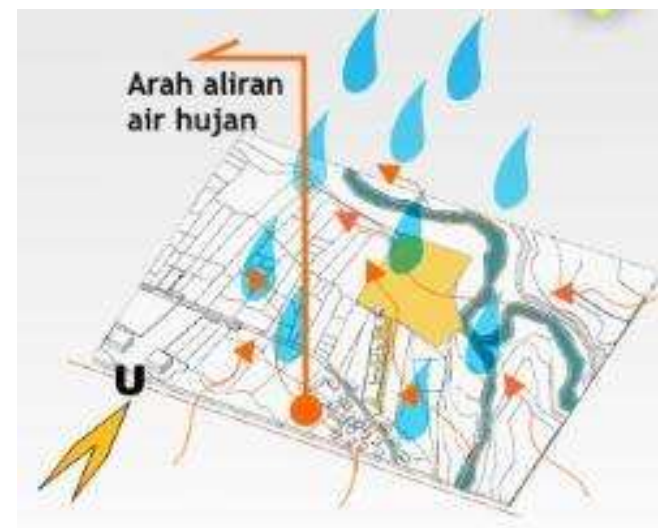

Gambar 6. Analisa Air Hujan

\subsubsection{Pergerakan Angin dan Kualitas \\ Udara}

Banyak sumber penghasil udara bersih yang mengandung banyak $\mathrm{O}_{2}$ di sekitar tapak. Polutan berasal dari kegiatan kendaraan yang melewati tapak (lihat Gambar.7).

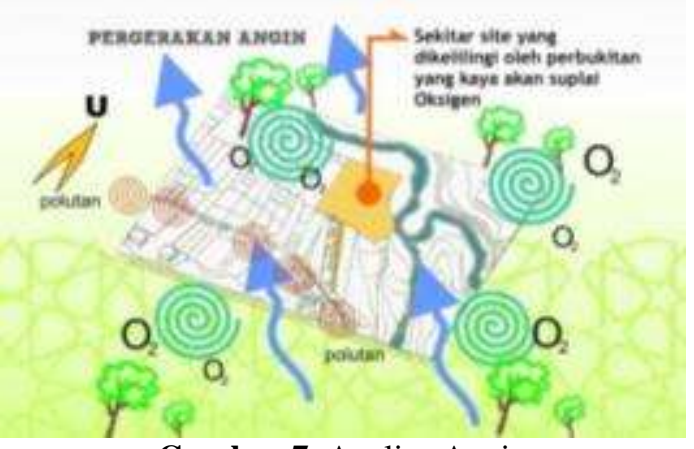

Gambar 7. Analisa Angin

1. Optimalisasi masuknya udara bersih ke dalam tapak;

2. Meminimalisir masuknya udara polutan yang mengarah kepada tapak;

3. Pemecah angin diperlukan untuk memecah arus angin yang cukup kuat pada malam hari.

\subsubsection{Kebisingan}

Sumber utama kebisingan adalah suara kendaraan dari jalan raya utama penghubung antar kota yang berada disebelah selatan tapak (lihat Gambar.8).

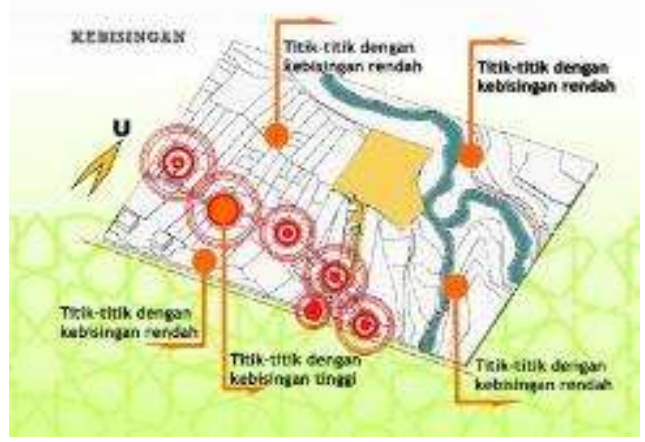

Gambar 8. Analisa Kebisingan

Meminimalisir masuknya suara bising yang mengarah kepada tapak.

\subsubsection{Vegetasi}

Tanaman yang dapat tumbuh pada tapak adalah tanaman yang dapat menyerap polutan, tidak beracun, tidak menimbulkan alergi, berwarna-warni dan dapat berbunga sepanjang tahun (lihat Gambar.9). 


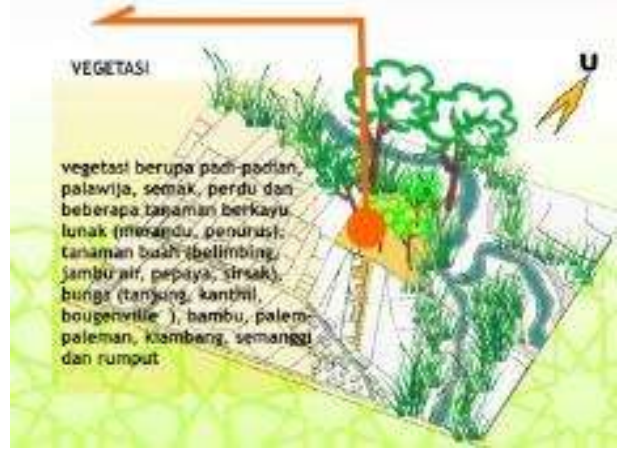

Gambar 9. Analisa Vegetasi

Jenis bunga yang ditanam antaranya adalah: Mawar, Matahari, Allium, Melati, Bougenvile, Kertas, Yure, dan Kamboja.

Jenis tanaman yang digunakan antaranya adalah: Rosemary, Kayu putih, Tanjung, Palem, Kanthil, Kenanga, Cemara udang danSerut

\subsection{Analisis Bentuk dan Orientasi}

\section{Bangunan}

\subsubsection{Tujuan}

Konsep bentuk dan tampilan yang mudah terlihat dan dikenali, menampilkan image pelayanan kesehatan Islami serta harmoni pada RSUI Madinah.

\subsubsection{Dasar pertimbangan}

Dipertimbangkan dari bermacam-macam gubahan, segiempat, dan lingkaran. Hal ini berdasarkan pertimbangan :

a. Islami - berkaitan dengan kiblat terkait aturan dan larangan terhadapnya

b. Efisien - tatanan ruang harus seefisien mungkin untuk kemudahan akses pertolongan dalam kondisi darurat

c. Healing - tatanan ruang yang mendukung kesembuhan/ pemulihan pasien

\subsubsection{Proses analisis}

Pada Gambar 10. menunjukkan eksplorasi bentuk bangunan

Islami: tempat tidur menghadap kiblat Healing: setiap pasien memiliki jendela untuk akses keluar namun menimbulkan banyak struktur 'patahan' tidak stabil dan kurang efisien dalam beberapa kondisi darurat (penyelamatan pasien)

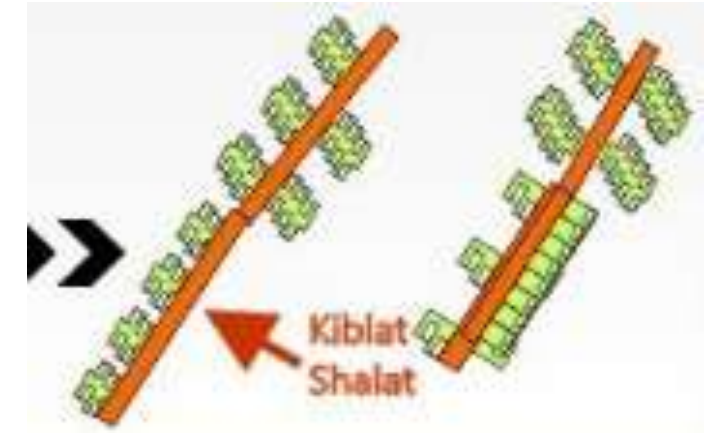

Gambar 10. Eksplorasi 1

Pada Gambar 11. menunjukkan eksplorasi bentuk bangunan

Islami: tempat tidur menghadap kiblat Healing: setiap pasien memiliki jendela untuk akses keluar, stabil dan lebih efisien dalam beberapa kondisi darurat (penyelamatan pasien).

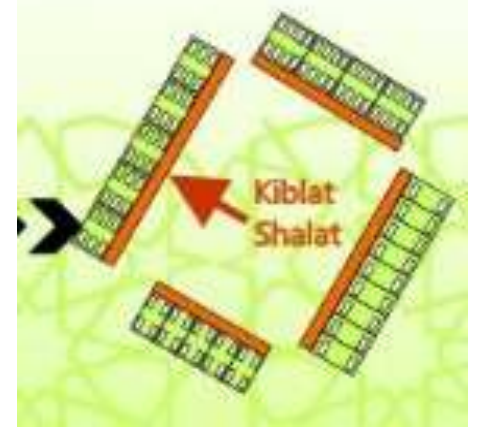

Gambar 11. Eksplorasi 2

\section{KESIMPULAN}

Konsep rancangan rumah sakit mengacu pada tata ruang interior dan eksterior yang mendukung proses kesembuhan pasien. Dari hasil analisa dan hasil korelasi dari beberapa data di atas, maka diperoleh hasil berupa rancangan Rumah Sakit Umum Islam di Kabupaten Malang sebagai berikut.

Nama RS : RSUI Madinah

Status : : Swasta

Kelas $\quad$ : B (Kemenkes, RI)

Lokasi : Jalan Raya Sukosari

Luas Lahan : $41.192 \mathrm{~m}^{2}$

Luas Bangunan : $26.259 \mathrm{~m}^{2}$

Daya Tampung : 300 Tempat Tidur

Kegiatan : Pelayanan Medis,

Penelitian dan Pendidikan

Konsep Healing Environment yang diterapkan pada tapak dan bangunan: 
1. Ruang Terbuka Hijau (RTH) sebesar $37 \%$ dari luas lahan untuk menciptakan lingkungan udara yang bersih dan sehat dengan suplai oksigen yang terjamin yang diwujudkan berupa taman, dan community garden (lihat Gambar 12 );

2. Pengadaan vegetasi berupa bunga dan pohon yang diposisikan sesuai pada tingkat ketahanan masing-masing jenis terhadap cuaca pada area RTH maupun balkon kamar inap untuk peredam panas bangunan sekaligus view ;

3. Pemanfaatan penghawaan alami pada kamar inap terhadap suasana lingkungan yang sudah dipersiapkan (lihat Gambar13 );

4. Pengadaan bukaan jendela dan pintu kaca pada setiap kamar inap yang memudahkan bagi setiap pasien untuk dapat mengakses pemandangan alami yang menyegarkan dan meredam stres;

5. Penggunaan warna ringan dan lembut berupa putih dan krem pada dinding, toscha pada tirai pembatas dan motif parquet kayu cerah pada lantai (lihat Gambar 14);

6. Penggunaan material kaca yang memberikan efek luas dan mengurangi kesesakan kamar inap.

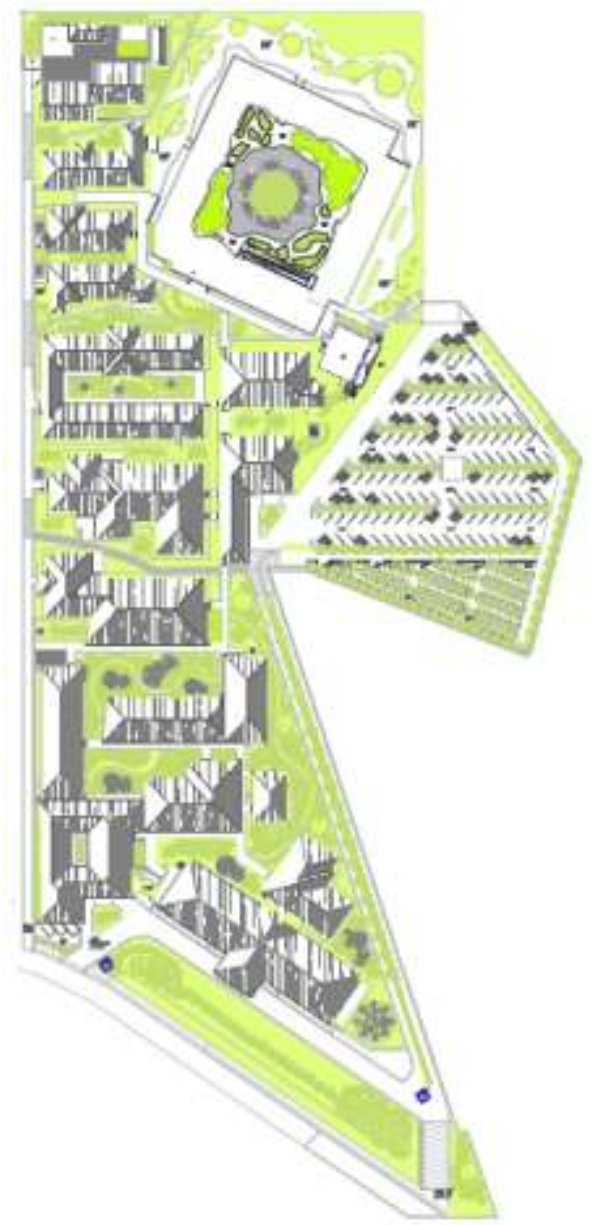

Gambar 12. Proporsi RTH pada tapak

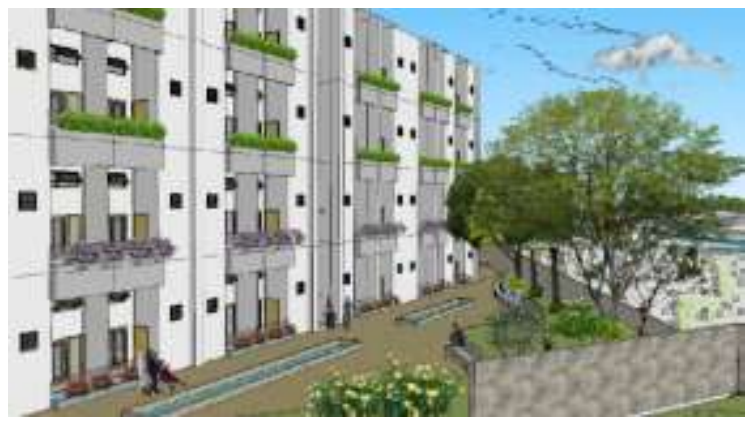

Gambar 13. Community Garden

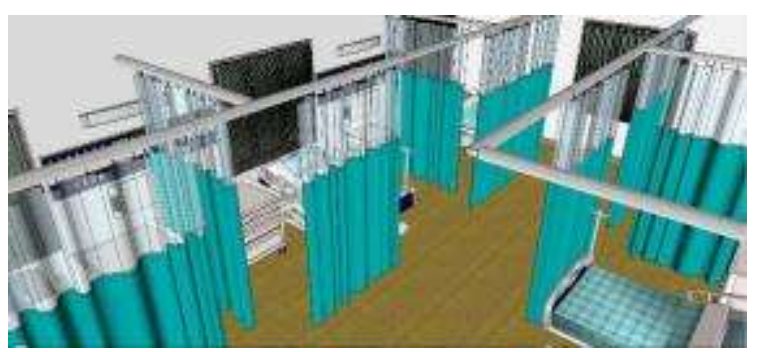

Gambar 14. Perspektif Interior 


\section{REFERENSI}

Departemen Kesehatan RI 2010. Pedoman Teknis Sarana dan Prasarana Rumah Sakit Kelas B. Jakarta

Kapasitas TT Jawa Timur http://sirs.buk.depkes.go.id, diakses pada 7 Desember 2014.

Lidayana, Vidra 2013 Jurnal: Konsep dan Aplikasi Healing Environment dalam Fasilitas Rumah Sakit, UNTAN

Ulrich, R. S. 2000. Effects of Healthcare Environmental Design on Medical Outcomes http://www.capch.org/wpcontent/uploads/2012/10/Roger-UlrichWCDH2000.pdf, diakses pada 4 Desember 2014 